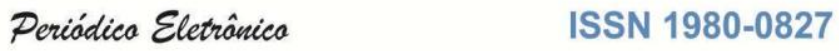

\section{PROGRAMA DE GESTÃO DE RESÍDUOS EM ESCOLA PÚBLICA - POLI USP RECICLA}

\author{
Welson G. Barbosa Jr ${ }^{1}$ \\ Pedro Paulo Consul Kassardjian ${ }^{2}$
}

\section{RESUMO}

Este trabalho teve como objetivo desenvolver uma sistematização de ações práticas educativas para instituições públicas de ensino médio para o gerenciamento de resíduos sólidos, de forma a capacitar os alunos nos procedimentos e práticas para implantação e operação de programas de reciclagem de resíduos. O projeto foi desenvolvido na Escola Estadual Prof. Renato de Arruda Penteado, com a formação de um grupo de trabalho para fomentar as ações de cultura e extensão por meio de um programa de educação ambiental e transferência do conhecimento na área de gestão de resíduos sólidos urbanos. A principal atividade realizada foi o inventário de resíduos, que contou com a presença dos alunos representantes do projeto. O inventário consistiu no levantamento de dados através de amostras de resíduos, de modo a obter as características qualitativas e quantitativas dos resíduos gerados na escola. Além disso, também foram desenvolvidas, com a participação dos professores, atividades didáticas como peças teatrais, semana do meio ambiente e palestras voltadas ao tema da gestão de resíduos. O desenvolvimento do projeto possibilitou a capacitação dos alunos nas práticas de gestão de resíduos sólidos e a implantação de um sistema de coleta seletiva na escola.

PALAVRAS-CHAVE: Educação Ambiental, Gestão de Resíduos, Escolas Públicas.

\section{INTRODUÇÃO}

Em 2010 foi aprovada a Lei Federal № 12.305/10, que estabelece a Política Nacional de Resíduos Sólidos (PNRS). A Lei criada pelo Ministério do Meio Ambiente é um marco histórico da gestão ambiental do Brasil. Até agosto 2014, a Lei determina que os governos estaduais e municipais deverão adotar o gerenciamento sustentável do "lixo". Para isso as prefeituras terão que elaborar um plano de resíduos sólidos. A lei também passa a exigir a colocação dos rejeitos em aterros sanitários regulamentados pelas normas ambientais. As ações realizadas pelas prefeituras seguirão ao conceito de gestão sustentável do lixo, proporcionando assim, a redução e a reciclagem dos resíduos através de coleta seletiva nas residências e com medidas que visem a erradicação dos lixões. Dentro deste contexto, o Programa de Gestão de Resíduos da Escola Politécnica da Universidade

\footnotetext{
${ }^{1}$ Escola Politécnica da USP - poli.usp.recicla@poli.usp.br

${ }^{2}$ Escola Politécnica da USP - poli.usp.recicla@poli.usp.br
} 
de São Paulo (Poli USP Recicla) propôs a criação de um projeto de educação ambiental para estabelecer um modelo de implantação de um programa de gestão de resíduos voltado para escolas públicas.

\section{OBJETIVOS}

O objetivo principal deste projeto foi desenvolver ações práticas educativas, inclusive de forma lúdica, sobre as questões ambientais na defesa da qualidade do meio ambiente, visando capacitar um grupo de jovens que estejam cursando da $1^{\underline{a}}$ à $3^{\text {a }}$ série do ensino médio público para que possam atuar diretamente em suas instituições, disseminando práticas sustentáveis de gestão de resíduos sólidos e aproximando instituições públicas de ensino. Além disso, as atividades desenvolvidas visaram igualmente o desenvolvimento das disciplinas relacionadas aos resíduos sólidos para todos os alunos da instituição de ensino médio em questão.

\section{METODOLOGIA}

Para formação do Grupo de Trabalho, foram selecionados dois discentes bolsistas regularmente matriculados em curso da Universidade de São Paulo e um docente formalmente vinculado à USP como coordenador. Como Instituição Participante, foi prospectada uma instituição pública estadual ou municipal que oferecesse curso de ensino em nível médio.

Ao longo dos 12 meses de duração da bolsa, as atividades foram basicamente divididas em duas etapas: planejamento do programa de educação ambiental e aplicação na Instituição Participante.

As diretrizes e atividades preestabelecidas que nortearam a etapa de planejamento do programa de educação ambiental foram: prospecção de possíveis instituições para serem contempladas com o programa; desenvolvimento de palestra para o entendimento das questões ambientais; desenvolvimento de um plano para a explicação sobre o funcionamento geral do Poli USP Recicla a todos os participantes; visita ao sistema de coleta seletiva da Escola Politécnica da USP; visita à instituição de ensino participante; elaboração colaborativa de um Plano de 


\section{Periódica Eletrônica \\ Fórum Ambiental}

da Alta Paulista
Volume 11, Número 08, 2015

Saúde e Saneamento Ambiental

Gestão de Lâmpadas Fluorescentes, Pilhas e Baterias e Resíduos Classe II (classificação da ABNT); prospecção de ecopontos para receber os tipos de resíduos contemplados no programa, bem como levantamento dos custos envolvidos.

As atividades da segunda etapa (aplicação na Instituição Participante) foram criadas e programadas com base em um Cronograma Modelo, que foi a referência desde o primeiro contato com a instituição de ensino participante até o encerramento das atividades colaborativas.

\section{RESULTADOS}

Escolheu-se a Escola Estadual Professor Renato de Arruda Penteado do município de São Paulo-SP para ser beneficiada com o projeto, na qual formou-se um grupo de 20 alunos que atuaram com multiplicadores do programa de gestão de resíduos. Foram comprados e instalados em locais estratégicos coletores específicos para o armazenamento dos resíduos recicláveis; um coletor para pilhas e baterias de 30L; dois coletores para lâmpadas fluorescentes (um para as queimadas e outro para as quebradas) e uma bituqueira.

A gestão de resíduos foi otimizada de forma a utilizar a separação dos mesmos em recicláveis e não recicláveis em substituição à separação clássica em 5 tipos de coletores diferentes. Dessa forma, reduz-se a mistura de resíduos e evita-se o esforça repetido de separação, pois geralmente os resíduos são separados novamente na cooperativa. Esta prática foi bem sucedida e pode ser recomendada para outras escolas públicas.

Foi realizado o primeiro inventário da Escola, com participação dos alunos, para identificar a quantidade e tipo de resíduo gerado pela escola. Os estudantes também foram educados sobre a forma correta de descarte do papel para reciclagem e sobre a redução na geração de resíduos, por exemplo, pela ampliação do uso de canecas plásticas duráveis.

Foi firmado acordo com uma Cooperativa para o tratamento dos resíduos recicláveis. Essa escola contou com a parceria da LOGA (Cooperativa Coletora de Resíduos), que através de uma palestra, trouxe informações importantes sobre descarte e coleta de resíduos. Foi firmado acordo com a Escola Politécnica para o tratamento das lâmpadas, pilhas e baterias. 
Observou-se que a metodologia aplicada na implantação do programa de gestão de resíduos atingiu e superou as expectativas iniciais. O cronograma foi cumprido e houve envolvimento e ampla colaboração da escola no projeto proposto, demonstrado pelo grande número de alunos participantes e atividades escolares realizadas com este tema. Recomenda-se, portanto, que a própria coordenação da escola defina um grupo de pessoas para implementar o programa. É importante que toda escola esteja envolvida com o programa e a presença de um ou mais professores é indispensável.

Todo o resíduo deve ser separado e armazenado de modo correto na própria escola. Após encontrar uma cooperativa ou empresa municipal de coleta seletiva capacitada e regulamentada segundo a legislação vigente, pode ocorrer o descarte final adequado. A parceria com a cooperativa é muito importante, pois, quando organizados desta forma, catadores têm o trabalho valorizado como agentes formais na gestão dos resíduos urbanos, com benefícios para a geração de renda e para a qualidade dos materiais separados. Os resíduos não recicláveis deverão ser coletados e destinados à coleta municipal de lixo. Em relação aos Resíduos Classe I Perigosos (lâmpadas fluorescentes; pilhas e baterias) devem ser usadas caixas armazenadoras específicas. A gestão dos resíduos eletrônicos, toners e cartuchos deverão ser feita separadamente.

O descarte dos resíduos Não-Perigosos não apresentou custo, podendo até gerar renda para a escola, porém ela deverá comprar os coletores e materiais de proteção individual. Para os Resíduos Perigosos como as lâmpadas, pilhas e baterias, pode ter um custo no descarte final, pois os processos de descontaminação e reciclagem desses resíduos são caros. No caso dos resíduos de logística reversa (resíduos eletrônicos, toners e cartuchos), a lei determina que eles sejam recolhidos pelos fabricantes. Já as pilhas e baterias poderão ser entregues em ecopontos espalhados em todas as cidades. Uma das alternativas para se evitar os gastos é buscar parcerias com instituições envolvidas com o processo de reciclagem, sejam as próprias cooperativas, universidades públicas ou empresas privadas. 


\section{Conclusão}

Esse projeto pode ser considerado um sucesso, embora não tenha sido possível realizar uma previsão do seu impacto devido à falta de tratamento dos resíduos da escola antes do projeto. O programa promoveu a mobilização da comunidade escolar para conscientização ambiental ao longo de um ano, onde os alunos puderam promover atividades como peças teatrais, semana do meio ambiente, palestras, informativos, pesquisa acadêmica, tudo voltado ao tema gestão de resíduos. As parcerias firmadas foram responsáveis pelo transporte, tratamento e disposição final dos resíduos gerados nos processos, fornecendo certificados de destinação adequada. A partir da realização sistemática dos procedimentos e do plano de gestão adotados pela escola, espera-se uma redução substancial da produção dos resíduos e a diminuição do impacto ambiental, que poderá ser constatado com trabalhos futuros.

\section{REFERÊNCIAS}

Associação Brasileitra de Normas Técnicas. ABNT NBR 10004 de 2004 . Classificação dos resíduos. Disponível em: <http://www.aslaa.com.br/legislacoes/NBR\%20n\%2010004-2004.pdf >. Acessado em: 18 de maio de 2013.

Compromisso Empresarial para Reciclagem (CEMPRE ). Política nacional de resíduos sólidos. Agora É Lei 2011. Disponível em: <http://www.mma.gov.br/port/conama/res/res02/ res31602.html> acessado em: 29 de junho de 2013. 